\title{
A Teaching Model of Fractions for the Early Grades of Mexican Primary Education
}

\author{
Rubí Real \\ Escuela Normal Superior de México \\ Olimpia Figueras \\ Centro de Investigación y de Estudios Avanzados del IPN
}

One of the main purposes of the overall research project that authors are carrying out is to develop a Local Theoretical Model (LTM) for fractions and rational numbers considering the following four components: Models for formal competence, Teaching models, Models for cognitive processes, and Models for communication. In this paper, a characterisation of the teaching model for fractions for the first three grades of Mexican primary school is described. The most relevant result is the aforementioned depiction of the teaching model for the so-called second period of basic education. Among others, the following characteristics were identified: different aspects of fractions are considered in activities and word problems, however, there is a lack of continuity in studying those aspects along the period; more tasks related to equally dividing a whole to represent part-whole relations through fractions should be included, and there is not a one-to-one correspondence between competencies established in study programmes and those promoted by textbooks' authors.

Keywords: Teaching models, teaching of fractions, textbook's analysis, fraction's aspects.

The complexity of the rational number concept in terms of its different meanings and uses is considered to be the genesis for students' difficulties. Kieren (1976) suggested seven interpretations for rational numbers: fractions, decimals, ordered pairs, measures, quotients, operators, and ratios. Later on, he distinguished four sub-constructs for rational numbers: measure, quotient, ratio number, and multiplicative operator (Kieren, 1988). Usiskin (1979) identified different uses of these numbers involved in situations of splitting up, rates, proportions, and in mathematical formulae, and equations. Rational number concept has been regarded also as a group of sub-constructs and integrated processes related to a wide range of basic concepts appearing in a variety of problem situations as pointed out by Lesh, Landau, and Hamilton (1980). 
While for these researchers there are different interpretations, uses, or sub-constructs of rational numbers, Freudenthal (1983) highlighted diverse fractions' aspects: fracturer, comparer, fracturing operator, fracturing relation, ratio relation, ratio operator, transformer, measurer, operator, and fraction as number which are involved in various phenomena organized by the fraction concept.

Research results related to those different interpretations, uses, subconstructs, or aspects of fractions and rational numbers influenced worldwide educational reforms in the 90s, which were designed to improve the teaching and learning of mathematical concepts. Particularly, curriculum designers posed their attention on fractions' contents.

Reforms of that type were carried out in Mexico in that decade, too. However, about sixty percent of secondary school students still kept obtaining low scores on items about fractions in national tests (Instituto Nacional para la Evaluación de la Educación [INEE], 2009 \& 2012; Secretaría de Educación Pública [SEP], 2011a). Even though the students study fractions from primary to secondary school, the above score results show that the teaching of the fraction concept has not been successful in those levels of education.

Taking into account research findings from Siegler et al. (2012), which states that the knowledge of division and fractions built up in the primary school are unique predictors for algebraic knowledge and general mathematics achievement, the following inference seems natural: more often than not, the Mexican low achievers in the subject of fractions will encounter hindrances in their mathematical performance in a higher education level.

Within this context, the authors of this paper decided to design a research project to characterise the current teaching model for fractions in basic education, to create complementary didactical sequences for improving the model, and to pilot the model in a classroom. The research project has two stages, one theoretical and the other empirical. In this paper, attention is centred on part of the theoretical stage; it refers to the teaching model of fractions designed in 2011 for basic education and used nowadays. In particular, the topic of this document is linked to the following research questions:

1. Which are the characteristics of the current teaching model for fractions and rational numbers for Mexican basic education?

2. What are the strengths and weaknesses of the aforementioned teaching model?

\section{Theoretical and Methodological Framework}

Filloy, Rojano, and Puig (2008) developed Local Theoretical Models (LTMs) as a theoretical and methodological framework for research in mathematics education (see Filloy \& Cols, 1999). The main idea of this framework is the following: the LTM is precisely what is built up to organize 
the research. Thus, LTMs are created to give an account of phenomena that appears in teaching and learning mathematics (Puig, 2003).

In the process of composing an LTM for an object of study, four interrelated components should be considered: (1) Models for formal competence, (2) Teaching models, (3) Models for cognitive processes, and (4) Models for communication.

According to Filloy et al. (2008), models for formal competence are referred to mathematical knowledge as a discipline, focusing on concepts, the structure of the concept, and their properties. The most important aspects of the construction of a mathematical concept serve to clarify didactical intentions in order to propose the characteristics needed to be a competent user of Mathematical Sign Systems (MSSs).

For introducing a notion of Mathematical Sign Systems in a broad sense, Puig (2010) argues that the signs used in mathematics are not all of a linguistic nature, so sign should not be considered in a linguistic perspective. He uses the term "expression" from the expression/content pair; a terminology introduced in semiotics that is more congruent with the ways mathematical educators refer to written forms, for example "arithmetical expressions". This researcher asserts, it is common to give a description of the language in which mathematical texts are written as composed of two sets of signs: one formed by those considered strictly "mathematical" and the other that corresponds to some "vernacular" language. From the viewpoint of signification processes part of the phenomena studied in mathematics education- this distinction ceases to be crucial. What seems to be crucial for Puig (2010) is "the sign system taken as a whole, and what must be described as mathematical is the system and not the signs, because the system is responsible for the meaning of the texts" (p. 4). This researcher affirms that: "...the interest for the development of mathematics education is the characteristics of these (mathematical) sign systems, which are due not just to the fact that they are sign systems, but also precisely to the fact that they are mathematical systems" (Puig, 2010, p. 4).

Teaching models' component deals with the teaching of a mathematical concept, linked to how the study of a concept is structured on the school system (Filloy et al., 2008). Another important element of this component is the use of different didactical resources to introduce the study of a mathematical concept starting from a concrete level and promoting gradual abstraction processes. The latter entails the appropriation of the MSSs associated with such concept.

Models for the cognitive processes, according to Filloy et al. (2008), are related to ways of mathematical thinking and mathematics communication (between individuals and between individuals and mathematical objects). These processes are refined through complex elements used when working with mathematics. Among such elements are processes of perception, analytical and synthesis, usage of heuristics to solve problems, and processes 
of generalisation and abstraction. That refinement requires a novel use of MSSs in the teaching and learning of mathematics as well as taking into account students' difficulties when they are working with certain systems or mathematical objects.

The production of texts that use MSSs to promote students' mathematical thinking as well as their communication using those systems are constituents of the Models for communication's component. Processes for decoding mathematical texts carried out by students and teachers in the construction of mathematical knowledge are also part of these models (Filloy et al., 2008).

The LTMs frame is used as a theoretical and methodological framework to organize the overall research project that authors of this paper are carrying out while bearing in mind its four components. In this context: Models for formal competence are related to fractions and rational numbers as mathematical objects -for example, fractions are considered as ordered pairs of whole numbers and rational numbers are considered to be elements of a field of quotients of fractions-. In the Teaching models and Models for communication components, those numbers are dealt with as teaching objects, and Models for the cognitive processes have to do with the mathematical concepts as learning objects.

We defined a specific methodology to structure each component of the LTMs. In this paper, only two components will be considered: Models for formal competence and Teaching models. A general description for building up the former and results related to the construction of the latter are considered in the following sections.

\section{Models for Formal Competence}

Models for formal competence for the overall research project were built taking as a starting point an example of a didactical phenomenology of fractions made by Freudenthal (1983). This specimen was reinterpreted identifying different classes of phenomena: description and comparison of quantities, magnitude values or objects, division of substances measured by magnitudes, distribution of quantities, measurement, and numbers as part of a numerical system. The first five classes were associated with five mathematical processes: describing, comparing, dividing, distributing, and measuring.

The sixth class of the phenomena is related to two ways of constructing rational numbers considered by Freudenthal (1983): An $a$ posteriori axiomatic way -as equivalence classes of fractions- connected with their algebraic nature; and an a priori genetic way (as a commutative semigroup) linked to ratio operator.

Mathematical processes and constructions were organised and schematised in a network of notions, concepts, and processes for fractions and rational numbers in which diverse aspects of fractions emerged: descriptor, 
comparer, fracturing operator or fracturing relation, ratio relation, ratio operator, transformer, fracturer, measurer, operator, and fraction as number. In Real \& Figueras (2015) a description of the network is detailed, including examples for all the aspects of fractions with their corresponding phenomena.

The network and its description are considered as theoretical and methodological tools for analysing teaching models. In Real, Gómez and Figueras (2013) and Figueras (2016), one can find examples of the use of this tool to characterise particular teaching models of fractions. In the following sections a description of how this framework is used for characterising the teaching model for the first three grades in Mexican basic education.

\section{Methods}

The following paragraphs contain a summary of the research background, data analysis, what is understood as a teaching model, the features considered by the authors to characterise a teaching model, and data analysis in terms of the theoretical framework.

\section{Research Background}

In Mexico, basic education -children 3 to 15 year-olds-is divided into four periods: the first period corresponds to Preschool education; the second one comprises the first three years of primary education; the third period encompasses the last three grades of primary school, and the fourth one comprehends secondary education. Authorities of the Ministry of Education (known in Spanish as SEP) publish a series of documents for teachers, in which a description for the rationale and national curriculum for basic education are made. Within those official papers, teachers get study programmes for each grade. In this programme, the teachers can find what is expected from children to learn. By means of SEP, textbooks are provided to all students; these books are unique and compulsory in primary school.

\section{Data Analysis}

To characterise the teaching model for fractions in basic education, study programmes (SEP, 2011b; 2011c, \& 2011d) and mathematics textbook units covering fractions (Castillo et al., 2011; Hernández-Soto et al., 2011a, 2011b) were analysed for first, second and third grades of primary school.

For Puig (2010) "a teaching model is a sequence of texts that are taken as textual spaces to be read/transformed into another textual space as the learners create sense in their readings" (p. 6). In this context, data for this part of the research are the mathematical texts that the textbooks' authors for the first three grades of primary school produce with the goal for favouring student's production of meaning and sense. That is, units of data for analyses are sequences of tasks produced by the authors to provide students with mathematical experiences for carrying out a learning process through the 
reading of the textbook. This process is a part of the teacher's practice in the classroom; however, characterisation of the teaching model in this paper is centred toward textbook productions of the authors in accordance with what is established in the study programmes.

Data was analysed throughout a triangulation method while taking into account the following five groups of features: (1) The aspects of fractions, the phenomena in which they appear, and mathematical processes considered in their study; (2) Didactical sequences that allow students to mathematically experiment different aspects of fractions to construct better mental objects from Freudenthal's point of view (1983); (3) Different languages involved in the didactical sequences; (4) Specific characteristics needed to be a competent user of the aspects of fractions immersed in the didactical sequences, in which an appropriate use of different languages is included, in particular, the MSS of fractions; and (5) Inherent relationships among the four features mentioned above.

Regarding different languages involved in didactical sequences of teaching models, the textbooks' authors may consider everyday language; graphical codes used in different plane representations of geometric figures and solids, weighing scales, diagrams or schemas; as well as the underlying language in the number line; and the MSS of fractions.

The characteristics needed to be a competent user of fractions according to a teaching model are associated with: a skilled use of those aspects of fractions, which are necessary to solve problems related to phenomena and mathematical processes, studied in the didactical sequences; a flexible employment of the different languages to represent actions carried out as a part of a mathematical process and its results, and the utilisation of the MSS of fractions as mathematical symbols at different abstraction levels.

\section{Findings}

In this paper, authors present the results referred to the characterisation of the teaching model of fractions and rational numbers for the first three grades of primary school. Those results are structured and described considering each one of the five classes of features prior considered.

\section{Characterisation of a Teaching Model for Fractions}

The study of fractions linked to the description of a quantity through another quantity and indirect comparison of quantities is part of the first grade programme (SEP, 2011b) -see results in Figure 1, indicated with rectangles coloured with the lightest tone of grey in the branches corresponding to Describing and Comparing processes-.

One of the lessons from the mathematics textbook for this grade (Castillo et al., 2011) includes activities in which fraction as descriptor and ratio operator are studied via the expression 'the half of.' For instance, in the 
fourth activity of that lesson, the fraction as a ratio operator is verbally characterised using this phrase (see Figure 2). Although this aspect of fraction is studied, the wording of those expressions that allows students to obtain the results demanded is not favoured. For example: 'the half of 56 is 28,' 'the half of 28 is 14,' and 'the half of 14 is 7.' The establishment of these relationships would be more useful than to draw 28, 14 and 7 circles to represent the marbles Diana, Luis and Carlos have.

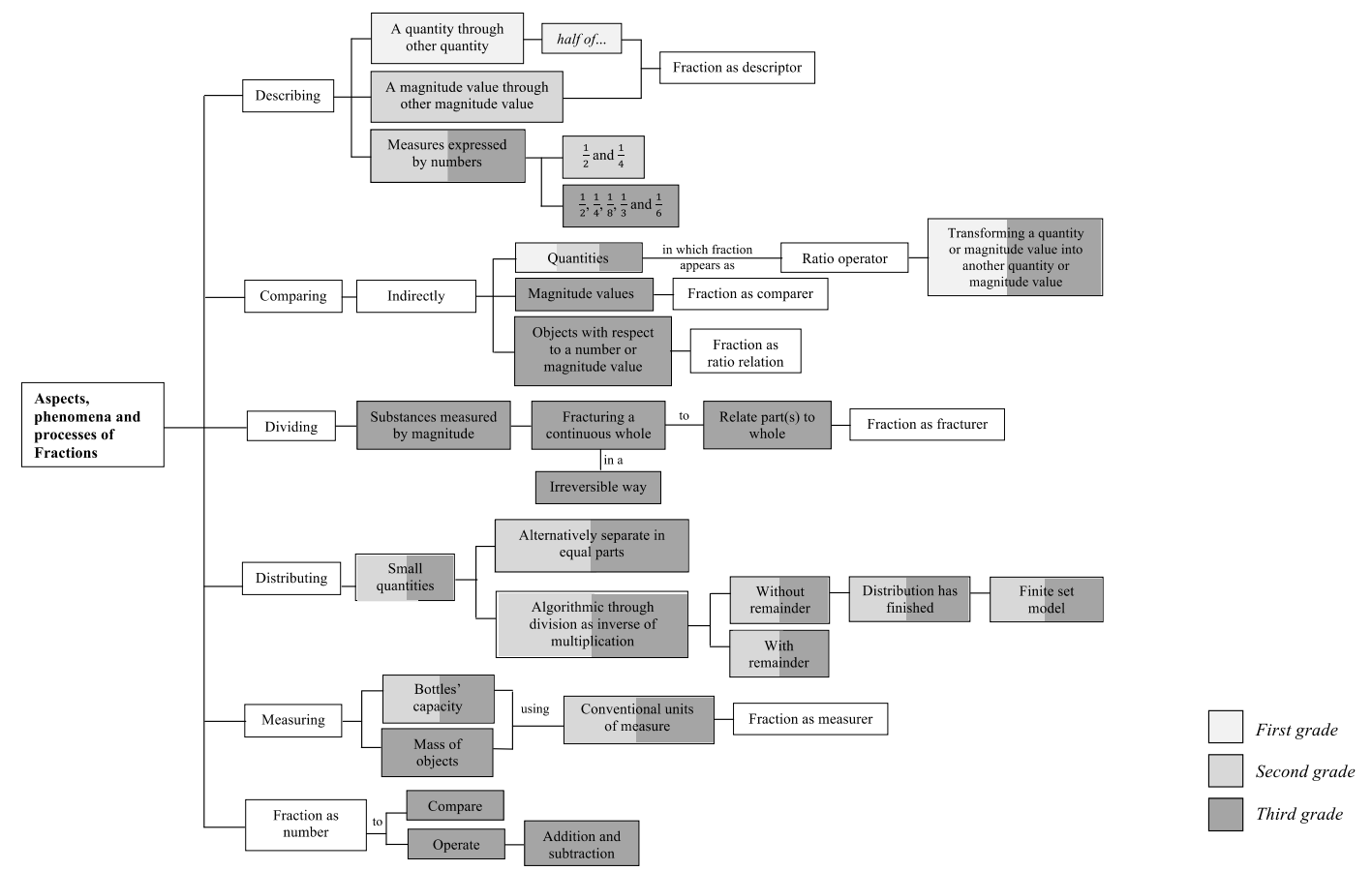

Figure 1. Aspects, phenomena, and processes included in the Teaching model for fractions in the three first grades of primary school.

In the second grade of primary school, fractions are not a part of the study programme (SEP, 2011c). Nevertheless, in the textbook (HernándezSoto et al., 2011a) authors include tasks that involve splitting up discrete sets and measuring the capacity of a bottle with conventional units; as well as the distribution of small quantities, though no reference is made to the use of a fraction as a descriptor of the result of the process (in Figure 1, these results are pointed out with rectangles coloured with a medium tone of grey in the branches corresponding to Describing, Distributing and Measuring processes).

An activity of a lesson from the textbook mentioned above involves splitting up a set of 40 objects into 10, 8, and 5 parts as can be seen in Figure 3. 


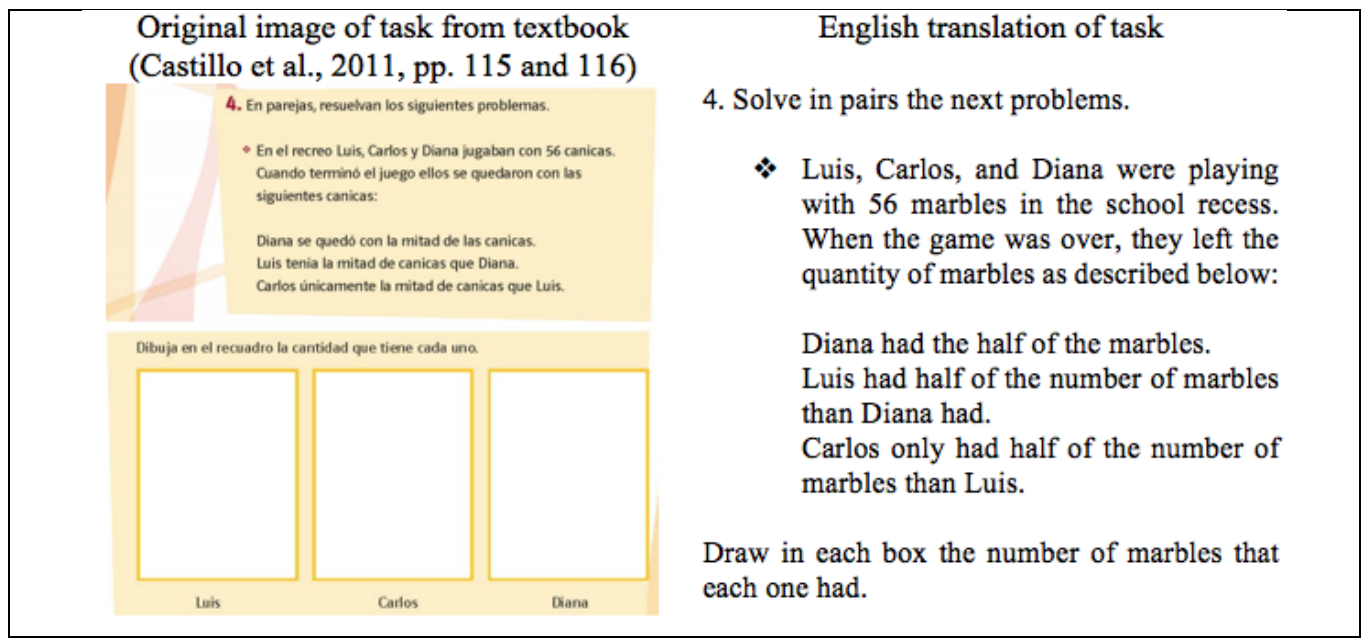

Figure 2. Fraction as ratio operator in the mathematics textbook for first grade.

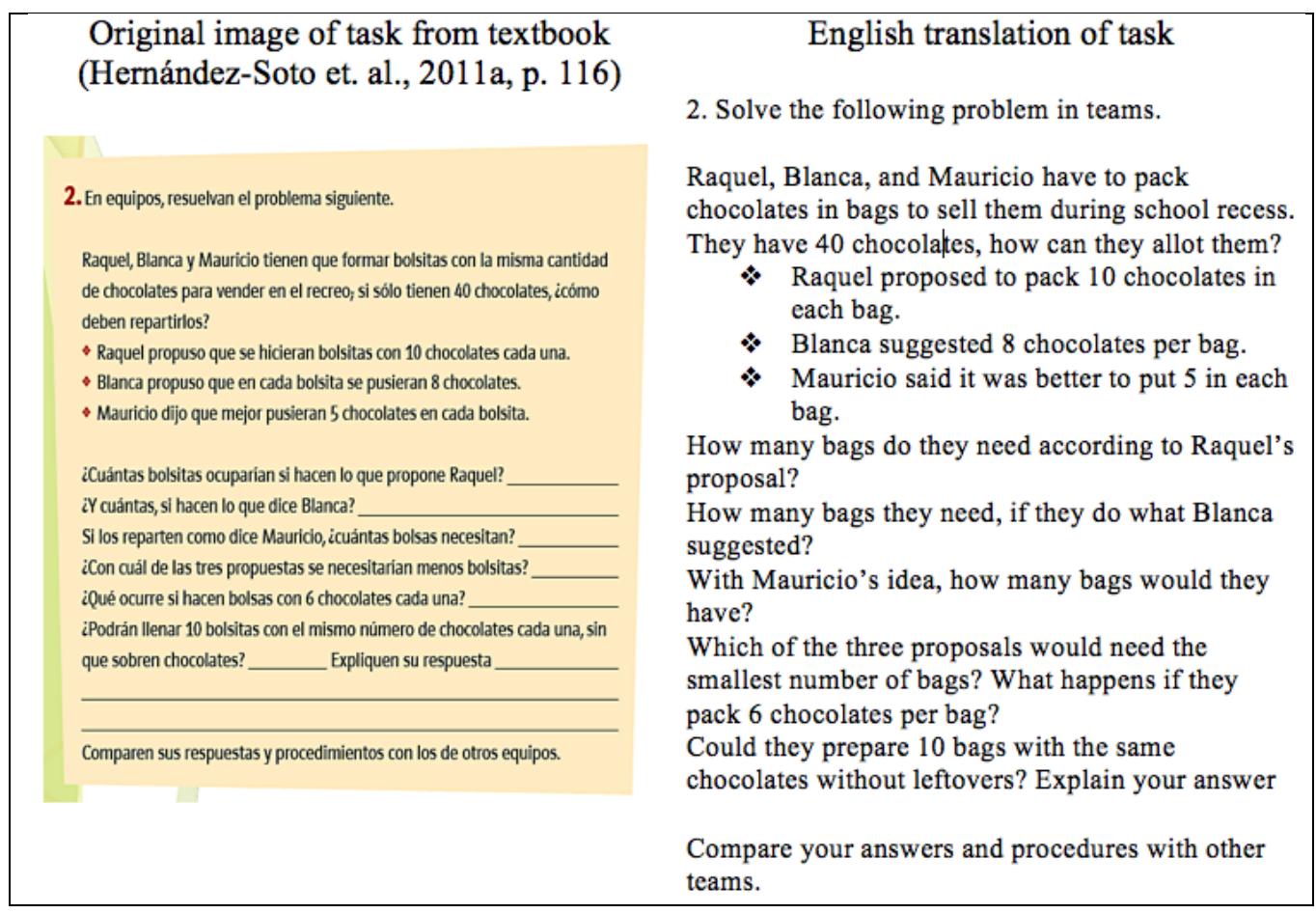

Figure 3. Activity that implies to allot in the math textbook for second grade.

As shown in Figure 3, the focus is on the whole numbers related to the result of distributing processes, but the relation between quantity to be shared and quantity associated with the result of that process is not taken into account. To consider those relationships, it would be necessary to describe the result of the sharing processes through the use of the expressions such as: 'with Raquel's proposal, each bag has one fourth of 40 chocolates,' 'with 
Blanca's suggestion, each bag gets one-fifth of all chocolates,' and 'with Mauricio's idea they will put one-eighth of 40 chocolates in each bag.'

The attention should be pointed toward the relationship $40=10+10+$ $10+10$ in the first case, which can be expressed as ' 40 is 4 times 10 ' to underline the multiplicative aspect of fractions so the expression ' 10 is the fourth part of 40 because 40 is 4 times 10' can be understood.

In third grade of primary school, according with the study programme (SEP, 2011d), the study of fractions includes the following objects: to describe a quantity or a magnitude value in terms of another quantity or magnitude value; to compare objects that are separated with respect to a number or a magnitude value; to transform a quantity or a magnitude value into another one. Some objectives are connected with distributing quantities; measuring the masses of objects using unconventional units; comparing fractions, and dividing a continuous whole in equal parts to relate the part(s) with the whole.

Fractions as numbers and their use in operations are also studied. See these results in Figure 1, indicated with the darkest grey rectangles in all the branches.

\section{Didactical Sequences: Experiment Different Aspects of Fractions}

In the teaching model for early grades of Mexican primary school, elements of five mathematical processes are considered. This can be an appropriate feature of the current teaching model of fractions. The following aspects of fractions are studied: descriptor, ratio operator, ratio relation, measurer, fracturer, and fraction as number, which appear from the simplest to the most complex top-down in Figure 1. Despite this, the textbooks' authors did not consider such types of phenomena as: description of cyclic and periodic processes, and descriptions of ratios; comparison of quantities and magnitude values through expressions used in everyday language; direct comparisons of objects, and measuring of magnitudes using the number line.

Moreover, a lack of continuity in the study of different aspects of fractions was identified. For example, the study of describing a quantity through another quantity is present in first grade, but this process is not incorporated in second and third grades (see Figure 1). The use of fractions to describe measures is a part of the activities for second and third grades. Fraction as ratio operator that is used to transform a quantity or magnitude value into another one is taught in first and third grades, but not in second grade. The fraction as ratio relation is studied only in third grade. Even though, activities in second and third grades favour the distributing of small quantities, the use of fractions to describe the result of sharing did not play a relevant role in second grade. The measuring of the capacity of recipients using unconventional and conventional units is taught in second and third grades while measuring masses of objects is only considered in third grade. Other magnitudes linked to fractions are not examined. The study of dividing 
the whole in equal parts is conducted solely in third grade and there are only two tasks that allow students to mathematically experiment with a fraction as a fracturer. In few cases, the textbook's authors propose students to divide the whole into equal parts. This weakness of the teaching model can lead to a limited construction of mental objects of fraction because partitioning is considered as an essential element for the dividing process present in the network and as a constructive mechanism of fraction knowledge (Kieren, 1988).

\section{Different Languages Involved in Didactical Sequences}

In first grade, authors of the textbook (Castillo et al., 2011) use everyday expressions as 'I cut half of the apples my mother cut' and 'my father cut the double of pears my sister cut'. The third grade textbook (Hernández-Soto et al., 2011b) contains circles and rectangles divided into equal parts where some parts are coloured to represent the part-whole relationship (see Figures 4 and 5). This representation is the most frequently utilised in tasks and is related to the translation from a graphical language to a symbolic language linked to processes of decoding and codification in different languages. In particular, as can be seen in Figure 4, two circles, one divided into 6 parts and the other in 12, in which 3 and 6 parts are coloured respectively, are used to represent equivalent fractions.

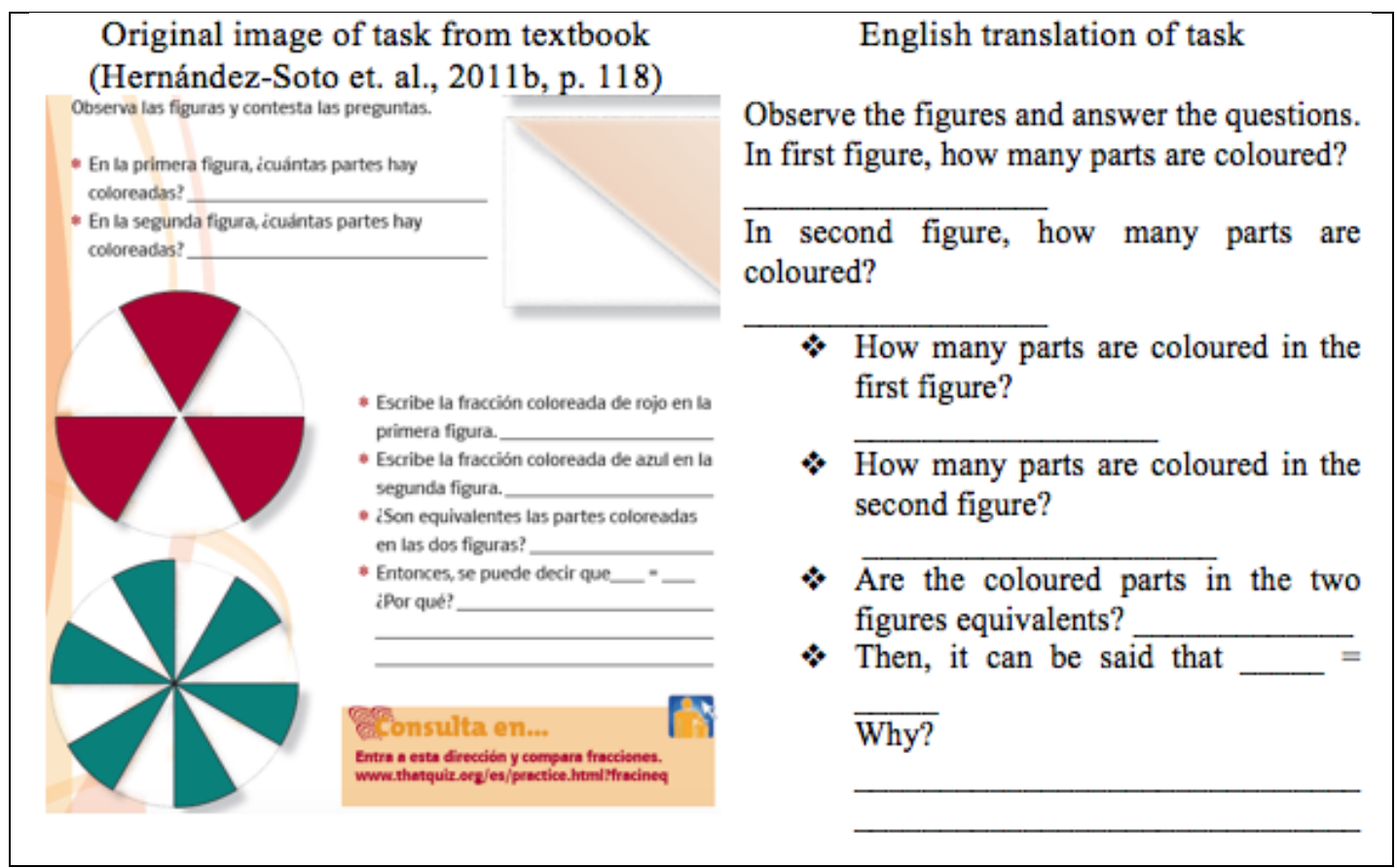

Figure 4. Geometrical figures representing part-whole relationships in the textbook for third grade. 


\begin{tabular}{|c|c|}
\hline $\begin{array}{l}\text { Original image of task from textbook } \\
\text { (Hernández-Soto et. al., 2011b, p. 148) }\end{array}$ & English translation of task \\
\hline 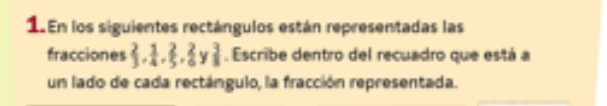 & 1. In the next rectangles, the fractions $\frac{2}{3}, \frac{1}{4}$, \\
\hline$\square$ & $\frac{2}{5}, \frac{2}{6}$ y $\frac{3}{8}$ are represented. Write in the box \\
\hline $\begin{array}{l}+1 \\
+1\end{array}$ & $\begin{array}{l}\text { aside of each rectangle the represented } \\
\text { fraction. }\end{array}$ \\
\hline
\end{tabular}

Figure 5. Geometrical figures representing part-whole relationships in the textbook for third grade.

In activities of the same textbook (Hernández-Soto et al., 2011b), diagrams and schemes serve to represent the masses of objects and the equivalence among them as well as to visualise the results of a distributing process (Figures 6 and 7). Students must select which scheme represents an equitable and exhaustive sharing of 3 tangerines among 4 persons adequately. The textbook's authors propose three options: (1) divide each tangerine into 4 equal parts and give one of these to each person; (2) give one tangerine to each of three persons, the other one would not get a share, and (3) give one tangerine to each of two persons and then divide the other tangerine into two equal parts and give half of 1 tangerine to each of the other two persons (see Figure 6).

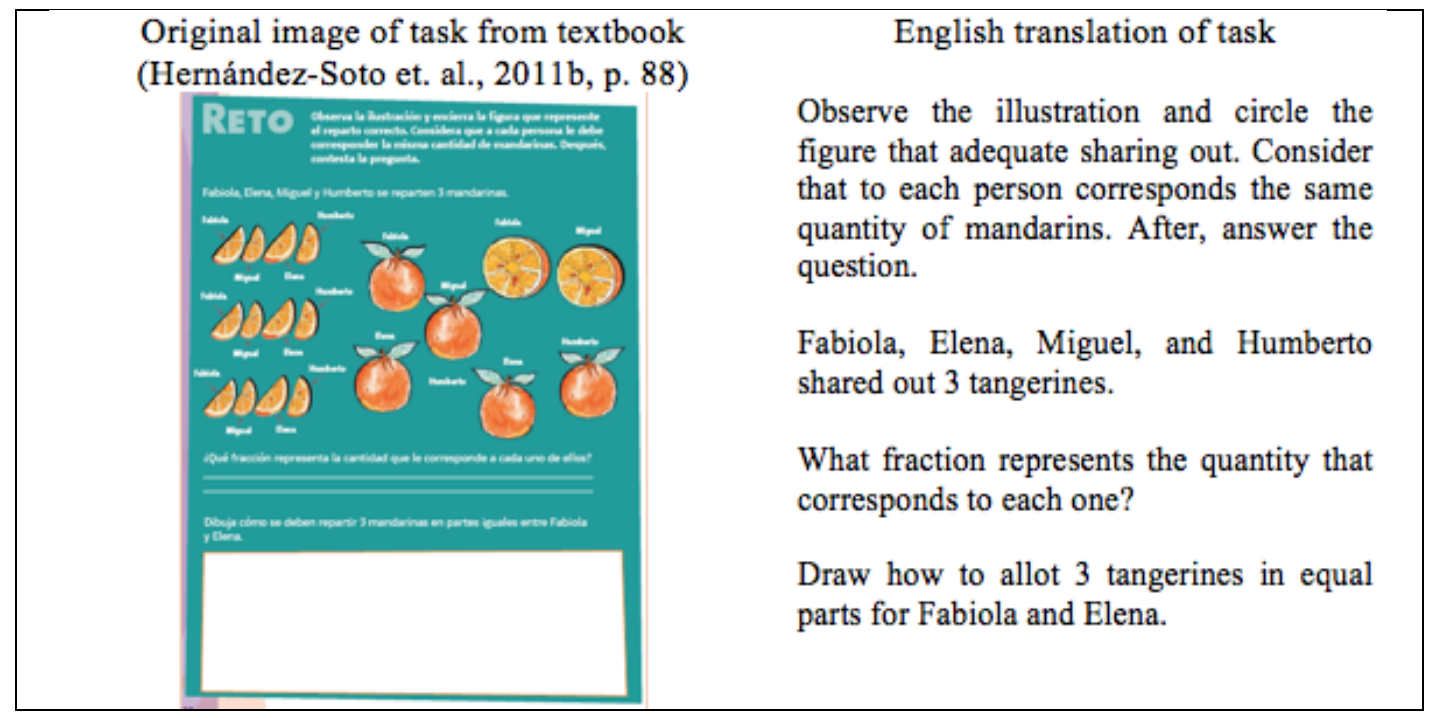

Figure 6. Schemes associated with the result of a distributing process that is included in the mathematics textbook for third grade. 
Diagrams and questions about fractions are useful to represent different wholes, compare objects on a magnitude value, and to conclude that the fraction $\frac{1}{2}$ represents the equivalent relationships among various quantities of mass (Figure 7). Complexity of those diagrams is connected with the relations between them. For example, the mass in bag $B$ is the half of the mass of bag A; the mass in bag $\mathrm{C}$ is one-fourth of the mass of bag $\mathrm{A}$; and the mass of two bags $\mathrm{C}$ is the same as the mass of bag $\mathrm{B}$. Although the diagrams that the authors of the textbook proposed are interesting, it is possible that students cannot understand the relations among them because the aspect of fraction as a comparer was not studied in first and second grades.

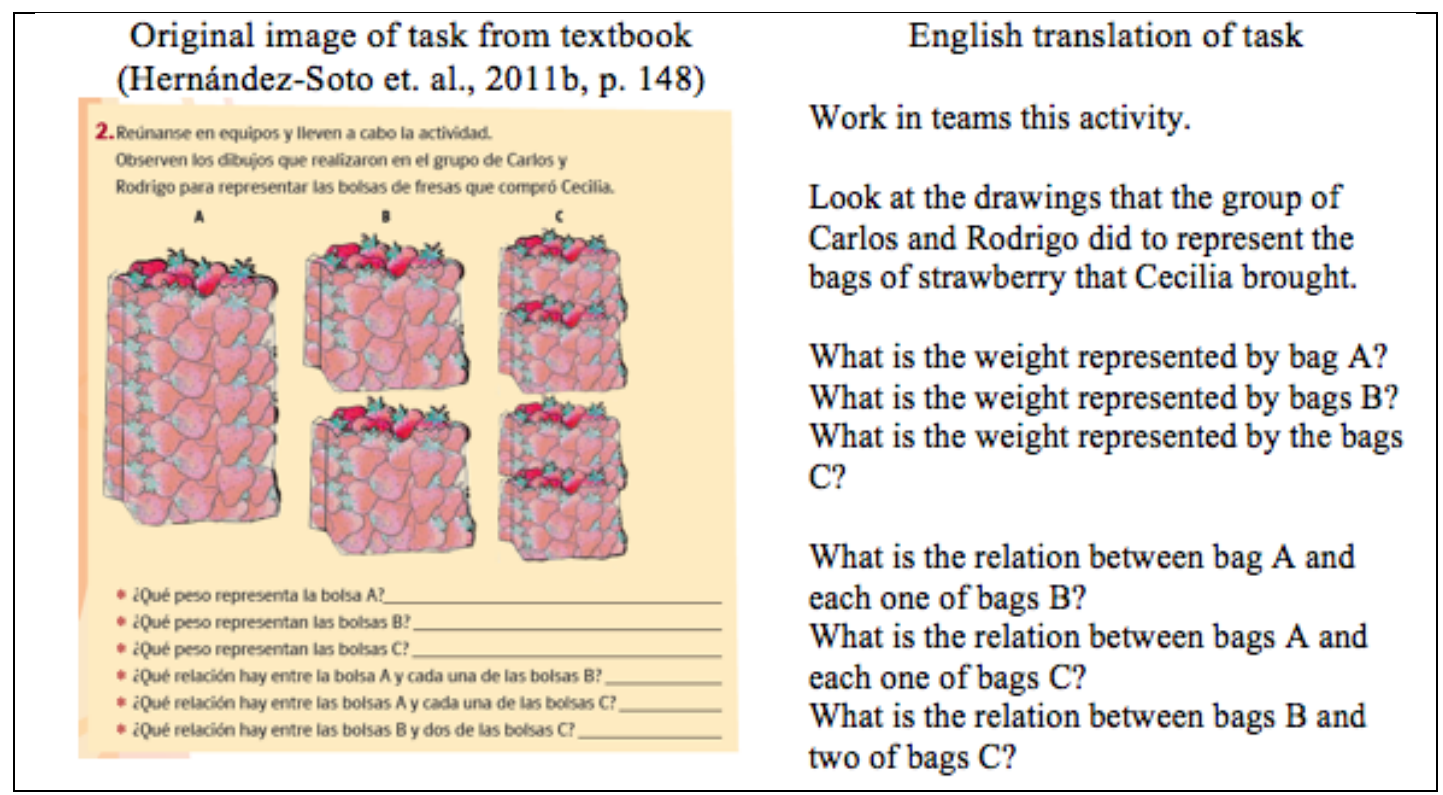

Figure 7. Diagrams related to the masses of objects and their equivalences that appear in the mathematics textbook for third grade.

An introduction to the arithmetical MSS of fractions and rational numbers is done in third grade. At first, it was introduced as a label for the capacity of bottles and later, as a representation of a part-whole relationship. Symbols for representing unit fractions' addition are used as well. Teaching model of fractions for the first three grades of primary school do not include plane representations using solids or weighing scales. In addition, the number line is not introduced as a teaching resource.

\section{Specific Characteristics: Competent User of Fractions' Aspects}

On the one hand, the competencies that appear in the study programmes (SEP, 2011b, 2011c, \& 2011d) were distinguished, and on the other, the competencies promoted within the mathematics textbooks (Castillo et al., 2011; Hernández-Soto et al., 2011a, 2011b) were identified. As can be 
seen from Table 1, a one-to-one correspondence between the competencies included in the study programmes (SEP, 2011b, 2011c, \& 2011d) and the competencies favoured by textbooks' authors in their didactical sequences does not exist. Three competencies in the study programmes are not considered in the textbooks while measuring capacity and mass are taken into account by textbooks' authors, but were not specified in the study programmes.

\section{Table 1}

Comparative Table of Competencies Outlined in the Teaching Model

Competencies in the study programmes Competencies that textbook's authors promote

\begin{tabular}{ll}
$\begin{array}{l}\text { Solving problems that imply } \\
\text { Determining and using the relation 'half } \\
\text { of.' }\end{array}$ & $\begin{array}{l}\text { Solving problems that use the } \\
\text { relation 'half of.' }\end{array}$ \\
\hline $\begin{array}{l}\text { Solving problems that use addition and } \\
\text { subtraction of fractions of the form } \frac{m}{2^{n}}\end{array}$ & $\begin{array}{l}\text { Solving problems and Doing } \\
\text { exercises, using addition and } \\
\text { subtraction of fractions of the form }\end{array}$ \\
when $1 \leq \mathrm{n} \leq 3$. & $\frac{m}{2^{n}}$ when $1 \leq \mathrm{n} \leq 3$.
\end{tabular}

Expressing fractions of the form $\frac{m}{2^{n}}$ verbally, as measures and as results of distributing processes.

\begin{tabular}{|c|c|}
\hline $\begin{array}{l}\text { Representing fractions of the above } \\
\text { form with symbols. }\end{array}$ & $\begin{array}{l}\text { Representing the result of a } \\
\text { distributing process or a relation } \\
\text { between the part(s) and a continuous } \\
\text { whole through a fraction. }\end{array}$ \\
\hline \multicolumn{2}{|l|}{$\begin{array}{l}\text { Identifying equivalent additive } \\
\text { representations. }\end{array}$} \\
\hline $\begin{array}{l}\text { Comparing fractions with the same } \\
\text { numerator or denominator. }\end{array}$ & $\begin{array}{l}\text { Comparing fractions to determine } \\
\text { which is the biggest. }\end{array}$ \\
\hline $\begin{array}{l}\text { Interpreting and Representing fractions } \\
\text { using diagrams or schemes. }\end{array}$ & \\
\hline
\end{tabular}

The mathematics textbooks for early grades of primary school (Castillo et al., 2011; Hernández-Soto et al., 2011a, 2011b) contain an introduction to the different aspects of fractions to solve a variety of tasks as mentioned before. To appreciate the fulfilment of the fourth group of features for the teaching model, it is necessary to have more information concerning the study programmes and the didactical sequences for fourth, fifth, and sixth grades. 


\section{Inherent Relationships}

Relationships between each of the different groups of features used to analyse the teaching model for the first three grades of primary education, underlies the description of each group. Those relations are an inseparable part of each of those groups. For example, didactical sequences are structured to produce sense regarding the aspects of fractions within situations in which phenomena and mathematical processes associated with different aspects of fractions are present.

\section{Discussion and Conclusion}

Considering the network of notions, concepts, and processes for fractions and rational numbers (Real \& Figueras, 2015) as result of building up the Models for formal competence component of the MTL and the first feature of the characterisation of a Teaching model, the aspects of fractions that are studied in the first three grades of primary school are the following descriptor, ratio operator, ratio relation, measurer, fracturer, and fraction as number.

A lack of continuity of the study of different aspects of fractions was identified in the didactical sequences of mathematics textbooks for the socalled second period of basic education. In particular, interruptions for studying fraction as a descriptor of measurements and as a result of a distribution process, fraction as a ratio operator, fraction as a ratio relation, and fraction as fracture were identified. The scarcity of activities that allow students to divide the whole into equal parts to represent part-whole relationships through a fraction constitutes a significant weakness of the teaching model. If there is a disruption of mathematical texts (in terms of Puig, 2010) that the authors of the textbooks propose for studying a fraction' aspect, it is possible that the student's production of meaning and sense of that aspect of fractions is not favoured. This lack of continuity in the studying of an aspect of fraction would not allow students experiment that aspect properly in a mathematical way.

There is a correspondence between the competencies established in the study programmes and those promoted by the authors of the textbooks, which proposes problems that involve the use of the expression 'half of' as a ratio operator as well as problems that involve adding and subtracting fractions. Likewise, correspondences were identified in the representation of a fraction as the result of a distribution process and as a part-whole relationship and in the comparison of fractions.

The characterisation of a teaching model for fractions made by authors of this paper allows: (1) teachers to identify weaknesses in the textbooks they are using with their students and design activities to overcome those gaps; (2) teacher trainers to revisit students' mathematical knowledge and teach pedagogical knowledge for teaching fractions; (3) curriculum designers and 
authors of textbooks to restructure the teaching of the mathematical contents along all the grades of basic education toward more gradual presentation of concepts; and, (4) researchers in mathematics education to build up an alternative teaching model, to experiment didactical sequences with students, to determine which aspects of fractions could be taught in each grade and to assess the learning of students related to the construction of better mental objects according to Freudenthal (1983) and the competent use in the sense of Filloy et al. (2008) of fractions.

It is important to highlight that the usability of the network of notions, concepts, and processes for fractions and rational numbers (Real \& Figueras, 2015) as a theoretical tool for analysing activities, didactical sequences or teaching models as well as for viewing the sequence and organization for studying fraction's mathematical contents have been proved. The network's use for designing activities and didactical sequences for teaching fractions and structuring teaching models is a promising tool, which has further implications for teaching and research.

\section{References}

Castillo, P. D., García, V. M., Hernández-Soto, J. M., Hernández-Castro, D. K., Perrusquía, E., León, M. A., Vázquez, E., Cantón, A. R., \& Osorio, M. T. (2011). Matemáticas. Primer grado. DF, Mexico: SEP.

Figueras, O. (1988). Dificultades en dos modelos de enseñanza de los racionales. (Unpublished doctoral dissertation). Department of Mathematics Education. DF, Mexico: Cinvestav.

Figueras, O. (2016). Modelos de enseñanza de las fracciones en los siglos XVI a XVIII: El caso del Dorado Contador. In E. Castro, J. L. Lupiañez, J. F. Ruiz \& M. Torralbo (Eds.). Investigación en Educación Matemática. Homenaje a Luis Rico. Granada, Spain: Comares.

Filloy, E., \& Colaborators. (1999). Aspectos teóricos del algebra educativa. Colección Sociedad Mexicana de Matemática Educativa. Serie Investigaciones en Matemática Educativa. DF, Mexico: Grupo Editorial Iberoamérica.

Filloy, E., Rojano, T., \& Puig, L. (2008). Educational algebra. A theoretical and empirical approach. New York, NY: Springer.

Freudenthal, H. (1983). Didactical phenomenology of mathematical structures. New York, NY: Kluwer Academic.

Hernández-Soto, J. M., García, V. M., Perrusquía, E., León, M. Á., Castillo, P. D., Vázquez, E., Cantón, A. R., \& Osorio, M. T. (2011a). Matemáticas. Segundo grado. DF, Mexico: SEP.

Hernández-Soto, J. M., García, V. M., Perrusquía, E., León, M. Á., Castillo, P. D., Hernández-Castro, D. K., \& Arredondo, C. (2011b). Matemáticas. Tercer grado. DF, Mexico: SEP. 
Instituto Nacional para la Evaluación de la Educación. (2009). El aprendizaje en tercero de secundaria en México. Informe sobre los resultados de Excale 09, aplicación 2008. Retrieved from http://publicaciones.inee.edu.mx/buscadorPub/P1/D/224/P1D224.pdf.

Instituto Nacional para la Evaluación de la Educación. (2012). Estudio comparativo del aprendizaje de tercero de secundaria en México 2005-2008. Español y matemáticas. Retrieved from http://mapeal.cippec.org/wp-content/uploads/2014/06/X-EXCALE3ro-ES-2005-2008-Estudio-comparativo.pdf.

Kieren, T. E. (1976). On the mathematical, cognitive and instructional foundations of rational numbers. In R. A., Lesh \& D. A., Bradbard (Eds.), Number and measurement. Papers from a research workshop (pp. 101-144). Columbus, OH: ERC/SMEAC.

Kieren, T. E. (1988). Personal knowledge of rational numbers: Its intuitive and formal development. In J. Hiebert \& M. Behr (Eds.), Number, concepts and operations in the middle grades (pp. 162-181). Reston. VA: Erlbaum \& National Council of Teachers of Mathematics.

Lesh, R., Landau, M., \& Hamilton, E. (1980, July). Rational number ideas and the role of representational systems. Paper presented at the 4th Conference of the International Group for the Psychology of Mathematics Education. Berkeley, CA. Retrieved from http://files.eric.ed.gov/fulltext/ED202692.pdf.

Puig, L. (2003). Signos, textos y sistemas matemáticos de signos. In E. Filloy (Ed.), Matemática educativa: aspectos de la investigación actual (pp.174-186). DF, Mexico: Fondo de Cultura Económica/Cinvestav.

Puig, L. (2010). Researching (algebraic) problem solving from the perspective of local theoretical models. Procedia Social and Behavioral Sciences, 8, 3-16. Retrieved from http://www.sciencedirect.com/science/article/ pii/S1877042810021075.

Real, R., \& Figueras, O. (2015). A network of notions, concepts and processes for fractions and rational numbers as an interpretation of didactical phenomenology. In K. Krainer \& N. Vondrová (Eds.), Proceedings of the Ninth Conference of the European Society for Research in Mathematics Education (pp. 346-353). Prague, Czech Republic: Charles University in Prague.

Real, R., Gómez, B., \& Figueras, O. (2013). Aspectos de la fracción en los modelos de enseñanza: El caso de un libro de texto. Épsilon, 30(3), 2136.

Secretaría de Educación Pública. (2011a). Evaluación Nacional del Logro Académico en Centros Escolares. Características generales e Información de los Reactivos Aplicados para su Uso Pedagógico. Primer Grado de Secundaria 2011. Retrieved from http://www.enlace.sep.gob.mx/content/ba/docs/2011/apoyos_uso_peda gogico/LibroENLACE_2011_1ero_SECUNDARIA_WEB.pdf 
Secretaría de Educación Pública. (2011b). Programa de estudios. Guía para el maestro. Educación Básica. Primaria. Primer grado. Retrieved from http://www.curriculobasica.sep.gob.mx/images/PDF/prog_prima ria/PRIM_1ro2011.pdf

Secretaría de Educación Pública. (2011c). Programa de estudios. Guía para el maestro. Educación Básica. Primaria. Segundo grado. Retrieved from http://www.curriculobasica.sep.gob.mx/images/PDF/prog_primaria/PR IM_2do2011.pdf

Secretaría de Educación Pública. (2011d). Programa de estudios. Guía para el maestro. Educación Básica. Primaria. Tercer grado. Retrieved from http://www.curriculobasica.sep.gob.mx/images/PDF/prog_primaria/PR IM_3ro2011.pdf

Siegler, R. S., Duncan, G. J., Davis-Kean, P. E., Duckworth, K., Claessens, A., Engel, M., Susperreguy, M. I., \& Chen, M. (2012). Early predictors of high school mathematics achievement. Psychological Science, 23(7), 691-697.

Streefland, L. (1993). Fractions: A realistic approach. In T. P., Carpenter, E., Fennema \& T. A., Romberg (Eds.), Rational numbers. An integration of research (pp. 289-325). Hillsdale, NJ: Erlbaum.

Usiskin, Z. (1979). The future of fractions. Arithmetic Teacher, 26, 18-20.

Authors:

Rubí Real

Escuela Normal Superior de México

Email: crealortega@gmail.com

Olimpia Figueras

Centro de Investigación y de Estudios Avanzados del IPN

Email:figuerao@cinvestav.mx 